\title{
Analisis Pendapatan Nelayan Rumput Laut Dan Nelayan Penangkapan Ikan (Study Kasus Kelurahan Takatidung Kecamatan Polewali Kabupaten Polewali Mandar)
}

\author{
Saharuddin $^{1}$, Ishak Manggabarani ${ }^{2}$, Takril $^{3}$ \\ Program Studi Agribisnis Fakultas Ilmu Pertanian Universitas Al Asy'ariah Mandar \\ 1aghasaharuddin@gmail.com \\ 2 ishakmanggabarani2@gmail.com \\ Takril_unasman82@yahoo.co.id
}

\begin{abstract}
Abstrak
Penelitian ini di laksanakan selama 3 bulan yakni dari tanggal 20 April sampai dengan 20 Juli 2016 di Kelurahan Takatidung Kecamatan Polewali Kabupaten Polewali Mandar. Penelitian ini bertujuan untuk mengetahui analisis pendapata nelayan rumput laut dan nelayan penangkap ikan di Kelurahan Takatidung. Metode yang digunakan dalam penelitian ini yakni metode secara acak atau sampling random dengan asumsi tiap nelayan memiliki kesempatan yang sama untuk di pilih sebagai sampel dari populasi nelayan rumput laut dan penangkapan ikan. Untuk menganalisis kelayakan usaha digunakan metode analisis pendapatan, R/C Ratio dan BEP. Hasil penelitian menunjukkan bahwa pendapatan yang di terima oleh nelayan rumput laut sebesar Rp 10,018,611 dengan R/C Ratio sebesar 1.6. Sedangkan pendapatan yang di peroleh oleh nelayan penangkap ikan sebesar Rp 3,125,835 dengan R/C Ratio sebesar 2.1. Maka dapat diambil kesimpulan bahwa, nelayan penangkapan ikan dan nelayan rumput laut sangat efektif di kembangkan karena nilai R/C Rationya tinggi.
\end{abstract}

Kata kunci: Pendapatan, Rumput Laut, Penangkapan Ikan

\section{PENDAHULUAN}

Sulawesi Barat merupakan salah satu daerah yang memiliki potensi hasil rumput laut dan ikan yang tinggi. Kelurahan Takatidung yang merupakan sentra rumput laut dan ikan yang ada di Sulawesi Barat. Salah satu komoditi unggulan sektor perikanan seperti rumput laut dan ikan telah menjadi salah satu sumber pendapatan bagi masyarakat Kelurahan Takatidung saat ini. Rumput laut dan ikan merupakan komoditi yang potensial dalam memberikan kontribusi bagi pendapatan masyarakat pesisir Kelurahan Takatidung. Komoditi rumput laut ini sudah lama dibudidayakan oleh masyarakat setempat.

Melimpahnya rumput laut dan sumberdaya ikan yang ada di Kelurahan Takatidung, maka perlu dilakukan kajian khusus bagaimana sumberdaya tersebut dapat dipasarkan dengan melihat potensi yang ada sehigga bisa terjual laku dipasaran. Untuk meningkatkan kualitas rumput laut dan ikan maka perlu penanganan yang baik agar dapat meningkatkan kualitas rumput laut dan ikan sehingga memiliki nilai jual yang tinggi.

Dengan meminimalkan biaya tanpa harus mengurangi jumlah produksi dan jumlah permintaan rumput laut dan ikan, maka akan terjadi pendapatan bagi nelayan. Oleh karena itu, penelitian ini dilakukan untuk mengetahui bagaimana pendapatan nelayan rumput laut dan penangkapan ikan yang ada di Kelurahan Takatidung.

\section{METODE PENELITIAN}

Penelitian ini akan dilaksanakan di Kelurahan Takkatidung, Kecamatan Polewali Kabupaten Polewali Mandar yang berlangsung selama 3 (tiga) bulan yakni dari tanggal April - Juli 2016.

Metode penelitian yang digunakan dalam penelitian ini adalah kuantitatif yaitu untuk mengetahui kelayakan usaha dari budidaya rumput laut dan penangkapan ikan. Untuk mengetahui apakah tersebut memperoleh keuntungan atau kerugian maka model analisis yang akan digunakan dalam penelitian ini sebagai berikut :

Analisis Pendapatan;

Soekartawi (2006) menyatakan untuk mengetahui besaranya pendapatan petani responden digunakan analisis pendapatanyang diformulasikan sebagai berikut :

$$
\pi=\mathrm{TR}-\mathrm{TC}
$$


Keterangan :

$\pi=$ Pendapatan (income);

$\mathrm{TR}=$ Total penerimaan (total revenue);

$\mathrm{TC}=$ Total biaya $($ total cost $)$.

\section{Analisis Revenue Cost Ratio (R/C Ratio);}

Menurut Sari (2011) R/C rasio merupakan metode analisis untuk mengukur kelayakan usaha dengan menggunakan rasio penerimaan (revenue) dan biaya (cost). Analisis kelayakan usaha digunakan untuk mengetahui apakah hasil nelayan tersebut memberikan keuntungan atau mengalami kerugian. Cara perhitungan R/C Ratio sebagai berikut :

$\mathrm{R} / \mathrm{C}=\underline{\text { Total Penerimaan }}$

Total Biaya Produksi

Kreteria kelayakan usaha adalah :

$$
\begin{aligned}
& \mathrm{R} / \mathrm{C}>1 \text { berarti layak } \\
& \mathrm{R} / \mathrm{C}<1 \text { berarti tidak layak (rugi) } \\
& \mathrm{R} / \mathrm{C}=1 \text { berarti impas }
\end{aligned}
$$

\section{Analisis Break Event Point (BEP)}

Menurut Soekartawi (2006) dalam Reny (2010), analisis BEP atau nilai impas adalah suatu teknis analisis untuk mempelajari hubungan antara biaya tetap, biaya variabel dan keuntungan. Volume penjualan BEP dalam penelitian merupakan pengukuran dimana kapasitas riil pengolahan bahan baku menjadi output menghasilkan total penerimaan yang sama dengan pengeluaran BEP dalam unit dan dalam rupiah yang dirumuskan sebagai berikut :

BEP Produksi $=$ Total biaya $/$ Harga penjualan

BEP Harga $=$ Total biaya $/$ Total Produksi

\section{Analisis Data Nelayan Rumput Laut dan Nelayan Penangkap Ikan di Kelurahan Takatidung.}

(a) Biaya Produksi

Tabel 4 : Rata-Rata Biaya yang Digunakan Oleh Nelayan Rumput Laut dan Nelayan Penangkap Ikan

\begin{tabular}{|c|c|c|c|}
\hline \multirow[b]{2}{*}{ No. } & \multirow[b]{2}{*}{ Uraian } & \multicolumn{2}{|c|}{ Total Biaya (Rp) } \\
\hline & & $\begin{array}{l}\text { Nelayan } \\
\text { Rumput } \\
\text { Laut }\end{array}$ & $\begin{array}{l}\text { Nelayan } \\
\text { angkap Ikan }\end{array}$ \\
\hline 1 & Biaya Tetap & $2,514,237$ & 905,801 \\
\hline 2 & $\begin{array}{l}\text { Biaya Tidak } \\
\text { Tetap }\end{array}$ & $14,767,152$ & $1,968,364$ \\
\hline Tota & Biaya & $17,281,389$ & $2,874,165$ \\
\hline $\begin{array}{l}\text { Sumbe } \\
\text { (b) Prc }\end{array}$ & $\begin{array}{l}\text { r: Data Primer Se } \\
\text { duksi }\end{array}$ & telah diolah, 2016 & \\
\hline $\begin{array}{l}\text { Tabel } \\
\text { dan } \\
\text { Takati } \\
\text { Mands }\end{array}$ & $\begin{array}{l}\text { 5. Rata-Rata Pro } \\
\text { Nelayan Penang } \\
\text { lung Kecamatan } \\
\text { r }\end{array}$ & $\begin{array}{l}\text { duksi Nelayan Ru } \\
\text { kap Ikan di } \\
\text { Polewali Kabupate }\end{array}$ & $\begin{array}{l}\text { nput Laut } \\
\text { Kelurahan } \\
\text { Polewali }\end{array}$ \\
\hline No. & Uraian & $\begin{array}{l}\text { Nelayan } \\
\text { Rumput } \\
\text { Laut }\end{array}$ & $\begin{array}{c}\text { Nelayan } \\
\text { Penangkap } \\
\text { Ikan }\end{array}$ \\
\hline 1 & Produksi (kg) & 3,640 & 240 \\
\hline 2 & Harga Jual (Rp) & 7,500 & 25,000 \\
\hline $\begin{array}{l}\text { Nilai } \\
\text { Rp }\end{array}$ & Produksi (1x2) & $27,300,000$ & $6,000,000$ \\
\hline
\end{tabular}
di Kelurahan Takatidung Kecamatan Polewali Kabupaten Polewali Mandar.
Sumber : Data Primer Setelah diolah, 2016

(c) Analisis Pendapatan dan R/C Ratio

Tabel 6 : Rata-Rata Pendapatan dan R/C Ratio Nelayan Rumput Laut dan Nelayan Penangkap Ikan di Kelurahan Takatidung Kecamatan Polewali Kabupaten Polewali Mandar.

\begin{tabular}{cccc} 
No. & Uraian & $\begin{array}{c}\text { Nelayan } \\
\text { Rumput } \\
\text { Laut }\end{array}$ & Nelayan \\
& & Penangkap Ikan \\
1 & Total Penerimai & $27,300,000$ & $6,000,000$ \\
2 & Total Biaya & $17,281,389$ & $2,874,165$ \\
\hline Pendapatan (1-2) & $\mathbf{1 0 , 0 1 8 , 6 1 1}$ & $\mathbf{3 , 1 2 5 , 8 3 5}$ & \\
\hline R/C Ratio (1:2) & $\mathbf{1 , 6}$ & & $\mathbf{2 , 1}$
\end{tabular}

Sumber : Data Primer Setelah diolah 2016 
(d) Break Even Point (BEP)

$$
\begin{aligned}
\text { 1. } \mathrm{BEP} \text { Produksi } & =\frac{\text { Total Biaya }}{\text { Harga Penjualan }} \\
& =\frac{R p 17.281 .165}{R p 7.500} \\
& =2.304 \mathrm{Kg}
\end{aligned}
$$

BEP Volume Produksi $=2.304 \mathrm{~kg}$, artinya bahwa dengan biaya Rp. 17,281,389 dan harga penjualan $\mathrm{Rp} 7.500$, nelayan rumput laut harus menghasilkan produksi sebesar $2.304 \mathrm{~kg}$ untuk balik modal. Keuntungan akan diperoleh ketika hasil produksi di atas dari $2.304 \mathrm{~kg}$.

\section{BEP Harga}

$$
\begin{aligned}
& =\frac{\text { Total Biaya }}{\text { Total Produksi }} \\
& =\frac{\operatorname{Rp~17,281,389}}{3,640 \mathrm{Kg}}
\end{aligned}
$$$$
=\mathrm{Rp} 4.748 / \mathrm{Kg}
$$

BEP Harga = Rp 4.748/kg, artinya bahwa

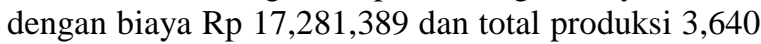
$\mathrm{kg}$, nelayan rumput laut harus menjual dengan harga Rp 4.748/kg untuk balik modal. Keuntungan akan diperoleh ketika harga jualnya di atas Rp 4.748/kg. BEP Produksi yang diperoleh nelayan budidaya rumput laut sebesar $2.304 \mathrm{~kg}$, sedangkan BEP harga adalah sebesar Rp 4.748/kg.

Dari hasil penelitian di ketahui bahwa, produksi rata-rata nelayan rumput laut di Kelurahan Takatidung sebesar 3,640 kg dengan harga penjualan sebesar 7.500/kg, hal ini membuktikan bahwa nelayan rumput laut di Keluratan Takatidung pada dasarnya sudah di atas dari titik impas produksi dan harga penjualan, ini berarti bahwa nelayan di Kelurahan Takatidung sudah mengalami keuntungan dalam melakukan produksinya. Sebab jika di bawah

\section{KESIMPULAN}

1. Total biaya yang dikeluarkan oleh nelayan rumput laut adalah sebesar Rp 17,281,389 dan total biaya nelayan penangkap ikan sebesar Rp 2,874,165. Sedangkan pendapatan budidaya rumput laut sebesar Rp 10,018,611 dan pendapatan nelayan penangkap ikan sebesar Rp 3,125,835

2. Nilai R/C Ratio untuk budidaya rumput laut sebesar 1,6 dan R/C Ratio nelayan penangkap ikan

\section{Penangkapan Ikan}

$$
\begin{aligned}
1 . \mathrm{BEP} \text { Produksi } & =\frac{\text { Total Biaya }}{\text { Harga Penjualan }} \\
& =\frac{R p 2.874 .165}{R p 25.000} \\
& =115 \mathrm{Kg}
\end{aligned}
$$

BEP Volume Produksi $=115 \mathrm{~kg}$, artinya bahwa dengan biaya Rp. 2,874,165 dan harga penjualan $\mathrm{Rp}$ 25.000, nelayan penangkap ikan harus menghasilkan produksi sebesar $115 \mathrm{~kg}$ untuk balik modal. Keuntungan akan diperoleh ketika hasil produksi di atas dari $115 \mathrm{~kg}$.

$$
\begin{aligned}
2 . \text { BEP Harga }= & \underline{\text { Total Biaya }} \\
= & \underline{\operatorname{Rp} 2,874,165} \\
& 240 \mathrm{Kg} \\
& =\operatorname{Rp} 11.975 / \mathrm{Kg}
\end{aligned}
$$

BEP Harga = Rp 11.975/kg, artinya bahwa dengan biaya Rp 2,874,165 dan total produksi $240 \mathrm{~kg}$, nelayan penangkap ikan harus menjual dengan harga Rp 11.975/kg untuk balik modal. Keuntungan akan diperoleh ketika harga jualnya di atas Rp 11.975/kg. BEP Produksi yang diperoleh nelayan penangkap ikan sebesar $115 \mathrm{~kg}$, sedangkan BEP Harga sebesar Rp 11.975/kg.

Dari hasil penelitian di diperoleh, produksi rata-rata nelayan penangkap ikan di Kelurahan Takatidung sebesar $240 \mathrm{~kg}$ dengan harga penjualan sebesar 25.000/kg, hal ini membuktikan bahwa nelayan penangkap ikan di Keluratan Takatidung pada dasarnya sudah di atas dari titik impas produksi dan harga penjualan, ini berarti bahwa nelayan di Kelurahan Takatidung sudah mengalami keuntungan dalam melakukan produksinya. Sebab jika di bawah dari titik impas baik dari produksi maupun harga penjualan maka akan mendapatkan kerugian.

sebesar 2,1. Sedangkan nilai break even point (BEP) Untuk nelayan rumput laut adalah BEP Produksi sebesar $2.304 \mathrm{~kg}$, BEP Harga sebesar $4.748 / \mathrm{kg}$, dan untuk break even point (BEP) penangkap ikan adalah BEP Produksi sebesar 115 $\mathrm{kg}$ dan BEP Harga sebesar 11.975/kg. 


\section{DAFTAR PUSTAKA}

Agung Lukito dan Surip Prayoga. Panduan Lengkap Usaha Perikanan (Jakarta Penerbit Swadaya ,2007)

Arikunto Suharsimi. 2010. Prosedur Penelitian Suatu Pendekatan Praktek, Jakarta: Penerbit Rineka Cipta
Soekartawi. 2006. Analisis Usahatani: UI Press, Jakarta.

Sari Reny Puspita. 2011. Analisis Nilai Tambah dan Kelayakan Usaha Agroindustri Chip Ubi Kayu Sebagai Bahan Baku Pembuatan MOCAF (Modified Cassava Flour) di Kabupaten Trenggalek. Malang. 